\title{
Cloninger'in Mizaç ve Karakter Boyutları ile Depresyon Arasındaki İlişsi: Gözden Geçirme Çalışması
}

\author{
Sinem CANKARDAŞ ${ }^{1}$
}

\begin{abstract}
Özet: Depresyonun risk faktörleri arasında kişilik önemli bir yer tutmaktadır. Depresyonun belirleyicileri açısından kişiliğin çalışılması hem depresyon için yüksek risk grubundaki kişilerin belirlenmesini sağlamakta hem de hastalık öncesi kişiliğin bilinmesi depresyonun etiyolojisini anlamak açısından bilgi sağlayıcı olmaktadır. $\mathrm{Bu}$ çalışmanın amacı Cloninger'in, mizaç ve karakterdeki normal ve anormal varyasyonları açıklayan çok boyutlu biyopsikolojik modelinden yola çıkarak hazırlanmış olan 'Mizaç ve Karakter Envanteri'nin (TCI) kişilik değişkenlerinin depresyon ile arasındaki ilişkiyi araştırmaktır. Yapılan araştırmada TCI ve depresyon arasındaki ilişkiyi ele alan 2005 - 2014 arasında yayınlanmış çalışmalar Web of Science, ScienDirect, GoogleScholar ve Ulakbim veri tabanlarında taranmıştır. Sonuçta yapılan çalışmanın kapsamına uygun olan hem yerli hem yabancı toplam 9 makaleye ulaşılmıştır. Araştırmalar bulguları bağlamında tartışılmıştır.Cloninger'in biyopsikolojik kişilik kuramının alt boyutlarından zarardan kaçınmanın yüksek oluşunun depresyon için risk arttırıcı bir faktör olduğu, kendini yönetme karakter boyutunun yüksek oluşunun ise depresyona karşı koruyucu bir faktör olduğu görülmektedir.
\end{abstract}

Anahtar Kelimeler: Depresyon, Mizaç, Kişilik, Karakter

\section{The Relationship Between Cloninger's Temperament And Character Dimensions And}

\section{Depression: Review}

\begin{abstract}
Personality is one of the important risk factors for depression. Studying personality to discover the determinants of depression is both useful to determine high risk population for depression and to understand the etiology of depression. The aim of this study is to explore the relationship between depression and personality dimensions in the light of Cloninger's psychobiological personality model. In this review, we searched the articles which examined the relationship between depression and Temperament and Character Inventory's subscales, published between 2005 - 2014years by using Web of Science, ScienceDirect, GoogleScholar and Ulakbim databases. As a result, it has reached both foreign and domestic total of 9article which appropriate to the scope of study. Research findings are discussed in the context. While the high level of harm avoidance personality dimension is a factor for increasing the risk of depression, high level of self- management personality dimension seems to be a protective factor against depression.
\end{abstract}

Key Words: Depression, Personality, Temperament, Character

${ }^{1}$ Dr.. İstanbul Arel Üniversitesi, Psikoloji Bölümü, Fen-Edebiyat Fakültesi, İstanbul-Türkiye

Address of correspondence/ Yazışma adresi: Dr. Sinem Cankardaş, İstanbul Arel Üniversitesi, Psikoloji Bölümü, Fen-Edebiyat Fakültesi, İstanbul-Türkiye. Email: sinemcankardas@arel.edu.tr

Date of received/ Geliş Tarihi: 13.06.2019,Date of acceptance/ Kabul Tarihi: 16.07.2019

Citing/ Referans Gösterimi: Cankardaş, S. (2019). Clonınger'in Mizaç ve Karakter Boyutları ile Depresyon Arasınki İlişki: Gözden Geçirme Çalışması. Kıbrıs Türk Psikiyatri ve Psikoloji Dergisi, 1 (2): 129-34 doi:10.35365/ctjpp.19.1.16 


\section{Giriş}

Depresif duygu durum yaşayan hastalarda kişilik bazı kişilik özelliklerinin varlığı tanımlanmış durumdadır. Buna rağmen belli bir kişilik yapısının varlığına ilişkin tartışmalar günümüzde de hala devam etmektedir (Öztürk ve Uluşahin, 2011). Literatürde duygu durum bozuklukları için çevresel ve bilişsel risk faktörlerinin üzerinde duran çalıșmalar yoğunlukta olsa da bazı kişilik özelliklerinin depresyona yatkınlığı arttırdığına dair çalışmalar da bulunmaktadır ve bu çalışmalarda bağımlılık, nevrotiklik, orallık, saplantılılık, kişilerarası duyarlılık gibi kişilik özelliklerinin depresyona yatkınlığı arttırdığı önerilmektedir (Boyce ve ark., 1991).

Kişilik ve depresyon arasındaki ilişki oldukça karmaşıktır. Kişilik özellikleri kişiyi depresyona yatkın hale getirebilir, depresyonun klinik seyrini ve görünümünü etkileyebilir ya da depresyon geçirildikten sonra kişilik değişime uğrayabilir (Akistal ve ark., 1983). Kişilik, depresyonun gelişimi ve etiyolojisi açısından dikkat edilmesi gereken bir faktör olarak görülmektedir ve bu nedenle de kişilik ile depresyon arasındaki ilişkiyi belirlemek önemlidir. $\mathrm{Bu}$ derleme çalışmasında da Cloninger'in çok boyutlu psiko-biyolojik modelinin önerdiği mizaç ve karakter değişkenlerinin depresyonu yordayıcılığını araştırmak amaçlanmıştır.

\section{Cloninger'in Kişilik Modeli}

Cloninger, somatizasyon bozukluğu ve yaygın anksiyete bozukluğu arasındaki farklılıkları açıklamak amacıyla kişilik yapısı üzerinde çalışmalar yapmış ve bu iki bozukluğa sahip hastalar arasında kişilik özelliklerinin farklılaştığını gözlemlemiştir. Bunun sonucunda hem normal hem de anormal kişiliklere uygulanabilecek bir model önermiştir (Köse, 2003).

Cloninger'in modelinde kişiliğin iki temel bileşeni olan mizaç ve karakterdeki normal ve anormal varyasyonlar çok boyutlu olarak tanımlanmıştır ve model beyindeki spesifik nörokimyasal transmiterlerin belirli bir uyarana nasıl tepki vereceğimizi belirlediği hipotezinden yola çıkarak oluşturulmuştur. Bu modele göre mizaç, yenilik arayışı, zarardan kaçınma, ödül bağımlılı̆g 1 ve sebat etme şeklinde dört boyutta tanımlanmıştır (Köse ve ark., 2004). Modelde bu dört boyut, nörokimyasal ileticilerle uyaran yanıt özellikleri eşlenerek tanımlanmıştır çünkü mizaç boyutlarının her biri özgül bir merkezi monoaminerjik sistem aktivitesi ile korelasyon göstermektedir (Cloninger, 1987). Buna göre mizaçın dört boyutu;

a) Yenilik Arayışı (Novelty Seeking): Dopamin: Davranışın Aktivasyonu

b) Zarardan Kaçınma (Harm Avoidance): Serotonin: Davranışın İnhibisyonu

c) Sebat Etme (Persistence): Norepinefrin: Davranışsal Süreklilik

d) Ödül Bağımlılığı (Reward Dependence): Norepinefrin: Ödülün harekete geçirdiği davranış yanıtı ve davranışın devamına genetik eğilimidir (Cloninger ve ark., 1993).

Cloninger'e göre mizacın bu alt boyutları genetik olarak birbirinden bağımsızdır ve yaşam boyunca durağandır, yani sosyokültürel etkiler karşısında değişmezlerdir (Arkar, 2010). Yenilik arayışı, davranışsal aktivasyon sistemi ile ilişkilidir ve yeni bir uyarana yanıtta keşfedici bir tutumla ilișkili genetik yatkınlık, dürtüsel karar verme, ödülle ilgili ip uçlarına yaklaşımda aşırıya kaçma, çabuk öfkelenme ile engellenmeden aktif kaçınmayı içerir. Zarardan kaçınma ise davranışsal inhibisyon sistemi ile ilișkilidir ve davranışın durdurulması ya da önlenmesi ile ilişkin genetik bir eğilimdir. Zarardan kaçınma, oluşabilecek sorunlara ilişkin karamsar bir endișelilik hali, belirsizliğe ilișkin korku, yabancılardan çekinme gibi pasif kaçınma davranışlarını içerir. Sebat etme, engelleyici ödül yokluğu durumlarıyla karşılaşıldığında davranışın sönmesine karşı genetik bir direnç gösterme eğilimi ile ilişkilidir. Ödül bağımlılı̆̆ ise, davranışı sürdürme sistemi ile ilişkilidir ve duygusallık, sosyal bağlanma, sosyal onaya bağımlılık ile görülen bir genetik eğilimdir (Cloninger, 1987).

Cloninger' in biyososyal kişilik modelinin revize edilmiş hali 'Mizaç ve Karakter Envanteri (TCI)' tarafindan yedi alanda (dört mizaç ve üç karakter boyutu) ölçülmektedir. Karakter boyutları da kendini yönetme (selfdirectiveness), iş birliği yapma (cooperativeness) ve kendini aşmadan (self-transcendence) oluşmaktadır (Gillespie ve ark., 2003). Cloninger, karakter boyutlarını sosyal ve bilişsel gelişim ve kişi-ötesi ve humanistik kişilik gelişimi açıklamarının sentezine dayanarak geliştirmiştir. Kendilik yönetme boyutu, bireyin kendini kabulü; iş birliği yapma boyutu diğer insanların kabulü ve kendini aşma boyutu ise bireyin kendini doğanın ve evrenin ne derece büyüklükte bir parçası olarak hissettiği ile ilişkilidir (Gillespie ve ark., 2003).

\section{Mizaç ve Karakter Envanteri (TCI)}

Mizaç ve Karakter Envanteri (TCI), Cloninger tarafindan, kendi kişilik kuramını temel alarak geliştirdiği bir ölçektedir. Ölçek toplam 240 maddeden oluşmaktadır ve 'Doğru' ya da 'yanlış' şeklinde yanıtlanan bir ölçektir. Birçok farklı dile çevrilmiş ve geçerlik ve güvenirliği yapılmış bir ölçektir. Ölçek 15 yaş ve üzeri bireyler için kullanılabilmektedir (Köse ve ark., 2004).

Ölçek Türkçe'ye ilk olarak Köse ve ark. (2004) tarafından çevrilmiş, geçerlik ve güvenirlik çalışması yapılmıştır. Köse ve ark.'nın (2004) çevirdiği ölçeğin Türkçe formu, Türkçe TCI olarak Cloninger tarafindan da onaylanmıştır ve Cronbach alfa değerleri mizaç boyutunda .60 ile .85 arasinda; karakter boyutunda ise .82 ile .83 arasında bulunmuştur. Ölçeğin Türkçe formunun faktör yapısı, geçerlik ve güvenirliği Arkar (2005) tarafindan sınanmış, mizaç ölçeklerinde cronbach alfa değerleri 0.55 ile 0.84 arasında iken, karakter ölçeklerinde .80 ile .84 arasında bulunmuştur. Hem Köse ve Sayar'ın (2004) hem de Arkar'ın (2005) gerçekleştirdiği geçerlik ve güvenirlik çalışmalarında ödül bağımlılığı ve sebat etme boyutlarının iç tutarlılığının zayıf olduğu gözlenmiştir. Sonuçta TCI ölçeğinin hem klinik uygulama hem de araştırmalarda kullanılabilir bir ölçek olduğu belirtilmiştir.

Mizaç ve Karakter Envanteri klinikte alkol bağımlılığı, yeme bozukluğu, kişilik bozuklukları, psikoz gibi birçok psikiyatrik bozukluğun kişilik ile ilişkisini araştırmak amacıyla kullanılmaktadır. Bu çalışmada da söz konusu envanterin depresif bozukluk ve kişilik arasındaki ilişkiyi araştırmak amacıyla kullanıldığı çalışmalar incelenmiştir. 


\section{Yöntem}

Gözden geçirme kapsamında, 2005 - 2014 yılları arasında, depresyon ve mizaç ve karakter boyutları arasındaki ilişkiyi ele alan, Mizaç ve Karakter Envanteri kullanmış çalışmalar "mizaç ve karakter envanteri, mizaç ve karakter boyutları, depresyon, kişilik, mizaç, karakter" kelimeleri kullanılarak Web of Science, ScienceDirect, GoogleScholar ve Ulakbim veri tabanlarında taranmıştır.

\section{Dahil Edilme Kriterleri:}

1. 18 yaş ve üzeri yetişkinlerle yürütülmüş olma,

2. Sağlıklı popülasyonda ya da klinik popülasyonda depresif belirti düzeyinin ölçülmüş olması,

3.Cloninger'in Mizaç ve Karakter Envanterinin ölçüm aracı olarak kullanılmış olması.

\section{Dışlama Kriterleri:}

Klinik popülasyonda Majör depresyona eşlik eden başka bir ruhsal rahatsızlığın (bipolar bozukluk, huzursuz bacak sendromu, yeme bozukluğu gibi) olması

1. Ölçüm alınan klinik ya da sağlıklı popülasyonun fiziksel bir hastalığının (diabet, kanser, kronik ağrı gibi) olmas

2. Erişilen yazının derleme ya da meta-analiz çalışması olmas1

Yapılan taramada belirlenen kelime gruplarından herhangi birini içeren 491 araştırmaya ulaşılmıştır. Bu kelime gruplarını birlikte içermeyen makaleler elendiğinde geriye 162 makale kalmıştır. $\mathrm{Bu} 162$ makaleden derleme ve meta-analiz çalışmaları çıkarıldığında geriye 156 makale kalmıştır. Dışlama ve dahil olma kriterleri göz önünde bulundurulduğunda çalışmanın kapsamına uygun, yerli ve yabancı toplam 9 çalışma değerlendirilmiştir. Taramada, aradaki ilişki henüz net olmamasına rağmen yapılan çalışmaların depresyon ve mizaç ve karakter özellikleri arasındaki ilişkiye yeterince odaklanmadığı görülmüştür.

\section{Kişilik ve Depresyon Arasındaki İlişki}

Ele alınan çalışmalara ait bilgiler, Tablo.1.de gösterildiği gibidir.

Tablo.1. Çalışmalara Ait Bilgiler

\begin{tabular}{|c|c|c|c|}
\hline & Örneklem Özelliği & Örneklem Sayısı & Değerlendirme Araçları* \\
\hline Cloninger ve ark.(2006) & Sağlıklı Yetişkin & 631 & CES-D, TCI \\
\hline Jylha ve Isometsa (2006) & Sağlıklı Yetişkin & 347 & BDÖ, BDA, TCI-R \\
\hline Nery ve ark. (2009) & $\begin{array}{l}\text { Majör Dep. Boz. Tanılı hasta grubu ve } \\
\text { Sağlıklı kontrol grubu }\end{array}$ & $60+60$ & HDÖ, TCI \\
\hline Rosenström ve ark. (2014) & Sağlıklı Yetişkin & 751 & BDÖ, TCI \\
\hline Çelikel ve ark. (2009) & $\begin{array}{l}\text { Majör Dep. Boz. Tanılı hasta grubu ve } \\
\text { Sağlıklı kontrol grubu }\end{array}$ & $81+51$ & HDÖ, BDÖ, TCI \\
\hline $\operatorname{Arkar}(2010)$ & Majör Dep.Boz. Tanılı hasta grubu & 147 & BDÖ, TCI \\
\hline Conrad ve ark. (2008) & Majör Dep. Boz. Tanılı hasta grubu & 394 & TCI, SCL-90-R, HDÖ \\
\hline Halvorsen ve ark. (2009) & $\begin{array}{l}\text { Majör Dep. Boz. Tanılı hasta ve sağlıklı } \\
\text { kontrol grubu }\end{array}$ & $90+50$ & TCI, BDÖ \\
\hline Farmer ve ark. (2009) & Sağlıklı Yetişkin & 591 & CES-D, TCI \\
\hline
\end{tabular}

*BDÖ = Beck Depresyon Ölçeği, BDA = Beck Anksiyete Ölçeği, HDÖ = Hamilton Depresyon Ölçeği, STAI = Durumluluk Kaygı Envanteri, CES-D = Epidemiyolojik Çalışmalar için Merkezi Depresyon Ölçeği, TCI = Mizaç ve Karakter Envanteri, SCL-90-R= Belirti Tarama Listesi-90.

(Cloninger ve ark., 2006) kişilik ölçümünün gelecekteki olası depresyonu yordayıp yordamadığının araştırmak amacıyla gerçekleştirdikleri çalışmada sağlıklı yetişkin örneklemi kullanılanarak toplam 631 kișiden bir y1l ara ile iki ölçüm almıştır. Sonuçta kişilik skorlarının temel oranının, bir yıl sonucunda depresyon düzeyindeki varyansın \%44'ünü açıkladığı görülmüştür. Mizaç boyutlarından zarardan kaçınma ve karakter boyutlarından kendini yönetmenin ise depresyon düzeyindeki değişimin \%52'sini açıkladığı görülmüştür. Buna göre kendini yönetmenin, depresyona karş1 koruyucu bir özellik olduğu, zarardan kaçınmanın isebireyleri duygusal olarak depresyona meyilli hale getiren bir özellik olduğunu bildirmiştir.

(Jylha ve Isometsa, 2006) mizaç ve karakter envanterinin boyutları ile depresyon ya da anksiyete semptomları arasındaki ilişkiyi araştırmak amacıyla gerçekleştirdikleri çalışmada TCI'nın boyutlarından kendini yönetmenin depresyon ve anksiyete semptomları ile negatif korelasyon gösterdiği, zarardan kaçınmanın ise depresyon ve anksiyete semptomları ile pozitif korelasyon gösterdiği bulgusuna ulaşılmıştır. Ayrıca zarardan kaçınma boyutunun ailedeki ruhsal bozukluk öyküsü ile ilişkili olduğu görülmüştür.

(Nery ve ark., 2009) majör depresif bozukluğa sahip olan kişilerle ve sağlıklı kontrol grubunu kişilik özellikleri açısından karşılaştırmak amacıyla gerçekleştirdikleri çalışmada majör depresif bozukluğu olan grubun sağlıklı kontrol grubuna göre yenilik arayışı, zarardan kaçınma ve sebat etmede daha yüksek skorlara sahip olduklarını; ödül bağımlılı̆̆ı, kendini yönetme ve iş birliği yapma skorlarının daha düşük olduğunu tespit etmişlerdir. Remisyonda majör depresif bozukluğu olan hastaların ise sadece kendini yönetme skorunun daha düşük olduğu 
gözlenmiştir. Zarardan kaçınma boyutunun depresyonun yoğunluğu ve epizotların sayısı ile pozitif korelasyon gösterdiği görülmüş; depresif epizotların sayısının artmasının zarardan kaçınmadaki artışla sonuçlanıyor olabileceği düşünülmüştür.

(Rosenström ve ark., 2014), kişilik özelliklerinin gelecekte klinik depresyon ya da disforik epizotları yordayıp yormadığını araştırmak amacı ile 15 yıllık bir boylamsal çalışma gerçekleştirmişlerdir. Çalışmada 751 kişilik genel popülasyon örnekleminden Beck Depresyon Ölçeği kullanılarak dört kez ölçüm alınmış, temel kişilik ölçümü ise TCI ile sağlanmıştır. Bununla birlikte birinci basamakta tedavi görmekte olan 93 depresif bozukluk hastasının 5 yıl ve 151 bipolar hastasının 1.5 yıl süre ile takibi yapılmıştır. Düşük kendini yönetme ile yüksek zarardan kaçınmanın gelecek disforiyi en iyi yordayan boyutlar olduğu belirtilmiştir. Fakat klinik örneklemde mevcut kişiliğin gelecek prognozu açısından bilgi sağlayıcı olmadığı görülmüştür. Sonuçta TCI'nin genel popülasyonda gelecekteki disforik epizotları tahminlediği ancak heterojen klinik örneklemde depresyonu tahminlemede zayıf bir yordayıcı olduğu gözlenmiş; kişilik ölçümünün klinik yordama yerine depresyon için riski belirlemede daha faydalı olacağı şeklinde yorumlanmıştır.

(Farmer ve ark., 2009) genel popülasyonda 4 yıllık boylamsal bir çalışma yapmış, mizaç ve karakter özelliklerinin depresif duygulanım ile ilişkisini incelemiştir. Araştırmada ilk ölçümlerde yaş ve cinsiyetin etkileri kontrol edildikten sonra mizaç ve karakter özelliklerinin depresif duygulanımdaki varyansın \%21'ini yordadığı görülmüştür. İkinci ölçümde elde edilen depresif duygulanımdaki varyansın \%6.5'inin ise TCI boyutları tarafindan yordandığı belirtilmiştir. Bu boyutlar arasından sadece zarardan kaçınmanın belirleyici bir değişken olduğu gözlenmiştir. Zarardan kaçınma ile ilişkili olarak beklenti endişesi ve dayanıklılığını yitirme yatkınlığının özellikle depresif duygulanım için bir risk faktörü olduğu sonucuna ulaşılmıştır.

Halvorsen ve arkadaşları (2009) hâlihazırda depresyon tanısı olan ve geçmişte depresyon tanısı almış kişilerle hiç depresyon geçirmemiş kişileri karşılaştırdığı çalışmada, TCI boyutlarının üç grupta farklılaştığını gözlemlemiş̧ir. Buna göre, hiç depresyon tanısı almamış kişilerin ödül bağımlılığı, yenilik arayışı, kendini yönetme, işbirliği yapma, sebat etme düzeylerinin depresyon tanısı olan ve geçmişte tanı almış gruptan daha yüksek olduğu; zarardan kaçınma ve öz-aşkınlık düzeylerinin ise diğer gruplardan daha düşük olduğu görülmüştür. TCI boyutlarının depresyonu yordama gücü incelendiğinde, zarardan kaçınma, sebat etme ve kendini yönetme boyutlarının depresyon düzeyindeki değişimi \%21 oranında açıkladığı görülmüştür.

Conrad ve arkadaşları (2008) intihar girişimi olan, intihar düşüncesi olan ve intihar düşüncesi olmayan majör depresyon hastaları ile yürüttüğü çalışmada intihar girişimi olanların zarardan kaçınma mizaç özelliğinin intihar düşüncesi olan ve olmayanlardan daha yüksek olduğunu gözlemlemiştir. Kendini yönetme karakter boyutunun ise hiç intihar girişimi olmayanlarda diğer iki gruptan daha yüksek olduğu görülmüştür.

Türkiye'de yapılan çalışmalar incelendiğinde, TCI ile yapılmış araştırmaların daha yakın zamanda ivme kazandığı göze çarpmaktadır (Çelikel ve ark. 2009).
Cloninger'in kişilik modeli ile depresyon arasındaki ilişkiyi belirlemek amacıyla yaptıkları çalışmada, depresyon hastalarının, zarardan kaçınma skorlarının sağlıklı kontrol grubundan daha yüksek; kendini yönetme skorlarının ise daha düşük olduğu belirtilmiştir. Beck Depresyon Envanteri'nin ödül bağımlılığı ve iş birliği yapma boyutları ile pozitif korelasyon, yenilik arayışı ve kendini yönetme boyutları ile de negatif korelasyona sahip olduğu belirtilmiştir. Araştırmacılar zarardan kaçınma ile depresyon arasındaki ilişkiyi doğruladıklarını ve kendini yönetme boyutları ile depresyon arasında ilişkiyi önerdiklerini belirtmişlerdir.

(Arkar, 2010) kişilik özellikleri ile depresyon arasındaki ilişkiyi belirlemek amacıyla yaptığı çalışmada depresyon puanlarının zarardan kaçınma mizaç boyutu ile pozitif, iş birliği yapma ve kendini yönetme karakter boyutları ile negatif korelasyon gösterdiği belirtilmiştir. Bulgular, depresif bozukluğa karşı yüksek kendini yönetme, yüksek iş birliği yapma ve düşük zarardan kaçınmanın dayanıklılı̆̆ 1 sağlayıc1 faktörler olduğu şeklinde yorumlanmıştır.

\section{Sonuç}

Cloninger'in biyopsikolojik kişilik kuramı, aile, boylamsal gelişim çalışmaları, kişilik yapısına ilişkin psikometrik çalışmalar,davranışsal koşullama ve öğrenme ile ilişkili nörofarmakolojik ve nöroanatomik çalışmalardan elde edilen bilgilerin sentezi ile oluşturulmuştur (Cloninger, 1987). Bu kuramdan yola çıkarak yine Cloninger tarafından oluşturulmuş olan Mizaç ve Karakter Envanteri, birçok dile çevrilerek geçerlik ve güvenirliği yapılmış hem normal hem klinik örneklemlerle yürütülen çalışmalarda kullanıma uygun bir ölçektir. Mizaç ve Karakter Envanteri alkol bağımlılığı,duygudurum bozuklukları, yeme bozuklukları, kişilik bozuklukları gibi farklı psikiyatrik bozukluklarla kişilik arasındaki ilişkiyi araştırmak amacıyla kullanılmaktadır.Bu çalışmada da Mizaç ve Karakter Envanteri boyutlarının depresyon ile ilişkisini araştırmak amaçlanmıştır.

Yapılan çalışmalara bakıldığında kendini yönetme karakter boyutunun depresyon açısından koruyucu bir faktör olduğu, zarardan kaçınma mizaç boyutunun ise depresyonda risk arttırıcı bir etmen olduğu görülmektedir. (Cloninger ve ark., 1993) zarardan kaçınma mizaç özelliklerine sahip kişilerin utangaç, korkulu, sosyal olarak inhibe ve pesimistik olarak tanımlanabileceğini belirtmiştir. $\mathrm{Bu}$ özellikler kişinin sadece depresyon değil diğer birçok bozukluğa yakınlığını da arttırmaktadır. (Jylha ve Isometsa, 2006) ise zarardan kaçınmanın aynı zamanda ailedeki ruhsal bozukluk öyküsü ile de ilişkili olduğunu belirtmiştir. Hem depresyon hem de intihar davranışı gözlemlenen hastalarda seratonerjik sistem disfonksiyonu ile zarardan kaçınmanın ilişkili olduğuna dair de literatürde birçok kanıt bulunmaktadır (Ebstein, 2006; Quilty, Godfrey, Kennedy ve Bagby, 2010). (Nevy ve ark., 2009), depresyon hastalarını remisyonda ve majör depresif epizotta olarak ikiye ayırdığında kişilik özellikleri açısından farklılaştıklarını görmüştür. Bu durumu kişilik envanterinin uygulandığı zamandaki duygudurumun kişilik özelliklerini etkiliyor olabileceği şeklinde yorumlamışlardır. Ayrıca zarardan kaçınma boyutunun depresyon epizotları arttıkça artıyor olabileceği görüşünü ileri sürmüşlerdir. Ancak (Farmer ve ark., 2009) 
yaptıkları boylamsal çalışmada, dört yıllık süre içinde depresif duygulanımı stabil olan ve değişiklik gösterenleri zarardan kaçınma açısından karşılaştırdıklarında; zarardan kaçınmanın mevcut duygu durumdan etkilenmediğini, daha stabil bir yapı olduğunu bulgulamışlardır. Benzer sonuçlar başka çalışmalardan da elde edilmiştir (Richter, Eisemann, Richter, 2000; Hirano ve ark., 2002). Tüm bu bulgular ışığında, yüksek zarardan kaçınmanın daha dirençli ya da ağır depresif epizotların ve intihar girişimleri için bir risk göstergesi olduğu söylenebilir.

Depresyonun bilişsel teorisi, depresyonun etiyolojisi ve gidişatını anlamada önemli bir yere sahiptir. Bilişsel süreçlerdeki işlev bozukluğunun olayları algılama, değerlendirme, yorumlama ve kodlamada çarpıtmalara ve bunun da depresyona neden olduğunu belirten bu yaklaşım (Beck, 1976) ile kişilik özellikleri arasında önemli bir ilişki vardır. Cloninger'in kendini yönetme karakter özellikleri de doğası gereği bilişsel özellikler göstermektedir. Bu karakter özelliği bireyin kendini kabulünü, amaç odaklılığını ve sorumluluğunu içermektedir. (Cloninger ve ark., 1993) kendini yönetmenin öz-yeterlilik kavramıla da çok yakın iliş̧kisinin olduğunu belirtmişlerdir. Bu bağlamda, kişinin kendi ve kendine ait özelliklerine ilişkin değerlendirmelerini içeren kendini yönetmenin düşük olmasının depresyon için bir risk faktörü olması anlaşılırdır. (Arkar, 2010), kendini yönetme karakter özelliğinin yüksek düzeyinin klinik örneklemde koruyucu bir faktör olabileceğini belirtmiş; (Karakaş ve Arkar, 2012) gençlerle yaptığ 1 çalışmada da benzer bir bulguya erişmiştir. Tüm bu bulgular 1şı̆̆ında, bilişsel terapinin kendini yönetme karakter özelliklerinin geliştirilmesi için etkili olabileceği ve önleyici olarak da kullanılabileceği düşünülmektedir. Diğer yandan zarardan kaçınmanın karamsar tutumlar, belirsizlik korkuları ve beklenti endişeleri üzerinde de bilişsel terapinin etkili olabileceği söylenebilir. Nitekim depresyonun tedavisinde farklı tedavi yaklaşımlarını karşılaştıran meta-analiz çalışmalarında da depresyonun tedavisinde bilişsel ve davranışçı terapilerin diğer yöntemlere göre daha etkili olduğu görülmektedir (Tolin, 2010).

Depresyon ile Cloninger'in biyopsikolojik kişilik modelinin boyutları arasındaki ilişkiye bakıldığında kendini yönetme karakter boyutunun yüksek olmasının depresyon için dayanıklılık sağlayıcı bir faktör olduğu, zarardan kaçınma mizaç boyutunun ise özellikle distimi gibi tekrarlı, uzun süreli ve intihar riski içeren depresyonda fenotipik bir özellik olabileceğinin farklı çalışmalar tarafından altı çizilmiştir. Ancak kişilik ölçümünün mevcut durumdaki duygudurumdan etkilenip etkilenmediği ya da ne derece etkilendiği net değildir. Bundan sonraki süreçte hem klinik hem normal popülasyonu içeren boylamsal çalışmaların yapılmasının, bu konuya açıklık getirebileceği düşünülmüştür.

\section{Kaynaklar}

Akiskal, H.S., Hirschfeld, R.M., Yerevanian, B.I. (1983) The Relationship of Personality to Affective Disorders. Archives of General Psychiatry; 40: 801-810.

Arkar ,H., Sorias, O., Tunca, Z., Şafak, C., Alkın, T., Akdede, B.B., Sahin, S., Akvardar, Y., Sarı Ö., Özerdem A., Cimilli C. (2005). Mizaç ve Karakter Envanterinin Türkçe Formunun Faktör Yapısı, Geçerlik ve Güvenilirliği. Türk Psikiyatri Dergisi, 16(3): $190-204$

Arkar, H. (2010). Depresif Duygudurum ile Kişilik Arasındaki İlişki: Beck Depresyon Envanteri ile Mizaç ve Karakter Envanteri'nin Karşılaştırılması. New Symposium Journal, 48(2): $116-121$.

Boyce, P., Parker, G., Barnett, B., Cooney, M., Smith, F. (1991). Personality as a Vulnerability Factor to Depression. British Journal of Psychiatry, 159: 106 - 114.

Cloninger, C.R. (1987). A Systematic Method for Clinical Description and Classification of Personality Variants: A proposal. Archives of General Psychiatry; 44: 573-588.

Cloninger, C.R., Svrakic, D.M., Przybeck, T.R. (1993). A Psychobiological Model of Temperament and Character. Arch Gen Psychiatry, 50: 975-989

Cloninger, C.R., Svrakic, D.M., Przybeck, T.R. (2006). Can Personality Assessment Predict Future Depression? A Twelvemonth Follow-up of 631 Subjects. Journal of Affective Disorders, 92: $35-44$.

Conrad, R., Walz, F., Geiser, F., Imbierowicz, K., Liedtke, R., \& Wegener, I. (2009). Temperament and character personality profile in relation to suicidal ideation and suicide attempts in major depressed patients. Psychiatry Research, 170(2-3), 212217.

Çelikel, F.C., Köse, S., Cumurcu, B.E., Erkorkmaz, U., Sayar, K., Brockardt, J.J., Cloninger, C.R. (2009). Cloninger's
Temperament and Character Dimensions of Personality in Patients with Major Depressive Disorder. Comprehensive Psychiatry, 50: 556-561.

Ebstein, R.P. (2006). The molecular genetic architecture of human personality: beyond self-report questionnaires. Molecular Psychiatry 11, 427-445.

Farmer, R. F., \& Seeley, J. R. (2009). Temperament and character predictors of depressed mood over a 4- year interval. Depression and anxiety, 26(4), 371-381.

Gillespie, N.A., Cloninger, C.R., Heath, A.C., Martin, N.G. (2003). The Genetic and Environmental Relationship Between Cloninger's Dimensions of Temperament and Character. Personality and Individual Differences, 35: 1931 - 1946.

Halvorsen, M., Wang, C. E., Richter, J., Myrland, I., Pedersen, S. K., Eisemann, M., \& Waterloo, K. (2009). Early maladaptive schemas, temperament and character traits in clinically depressed and previously depressed subjects. Clinical Psychology \& Psychotherapy: An International Journal of Theory \& Practice, 16(5), 394-407.

Hirano, S, Sato, T, Narita, T, Kusunoki K, Ozaki N, Kimura, S, Takahashi T, Sakado K, Uehara T. (2002). Evaluating the state dependence of the Temperament and Character Inventory dimensions in patients with major depression: a methodological contribution. J Affect Disord, 69:31-38.

Jylha, P., Isometsa, E. (2006). Temperament, Character and Symptoms of Anxiety and Depression in the General Population. European Psychiatry, 21: 389-395.

Karakaş, S., Arkar, H. (2012). Depresyon ve Kaygının Yordayıcısı Olarak Mizaç ve Karakter Boyutları. Türk Psikoloji Dergisi, 27(69): 21 - 30.

Köse, S. (2003). A Psychobiological Model Of Temperament and Charracter: TCI. Yeni Symposium, 41 (2): 86 - 97. 
Köse, S., Sayar, K., Ak İ., Aydın N., Kalelioğlu, Ü., Kırpınar, İ., Reeves R.A., Przybeck T.R. ve Cloninger C.R. (2004). Mizaç ve Karakter Envanteri (Türkçe TCI): Geçerlik, Güvenirliği ve Faktör Yapısı. Klinik Psikofarmakoloji Bülteni, 14: 107 - 131.

Nery, F.G., Hatch, J.P., Nicoletti, M.A., Monkul, E.S., Najt, P., Matsuo, K., Cloninger, C.R., Soares, J.C. (2009). Temperament and Character Traits in Major Depressive Disorder: Influence of Mood State and Recurrence of Episodes. Depression and Anxiety, 26: 382 - 388.

Öztürk, M.O., Uluşahin, A. (2011). Ruh Sağlığı ve BozukluklarıI. Nobel Tip Kitapevleri: Ankara.

Quilty, L. C., Godfrey, K. M., Kennedy, S. H., \& Bagby, R. M. (2010). Harm avoidance as a mediator of treatment response to antidepressant treatment of patients with major depression. Psychotherapy and psychosomatics, 79(2),116-122.

Richter, J, Eisemann, M, Richter, G. (2000). Temperament and character during the course of unipolar depression among inpatients. Eur Arch Psychiatry Clin Neurosci, 250:40-47.

Rosenström, T., Jylha P., Cloninger, C.R., Hintsanen, M., Elovainio, M., Mantere, O., Pulkki-Raback, L., Riihimak, K., Vuoriletho, M., Keltikangas, Jarvinen, L., Isometsa, E. (2014). Temperament and Character Traits Predict Future Burden of Depression. Journal of Affective Disorders, 158: 139 - 147.

Tolin, D. F. (2010). Is cognitive-behavioral therapy more effective than other therapies?: A meta-analytic review. Clinical psychology review, 30(6), 710-720. 